Complex Formation Between

O) Dimethyl Methylphosphonate and Hexafluoroisopropanol

Daniel C. Leggett

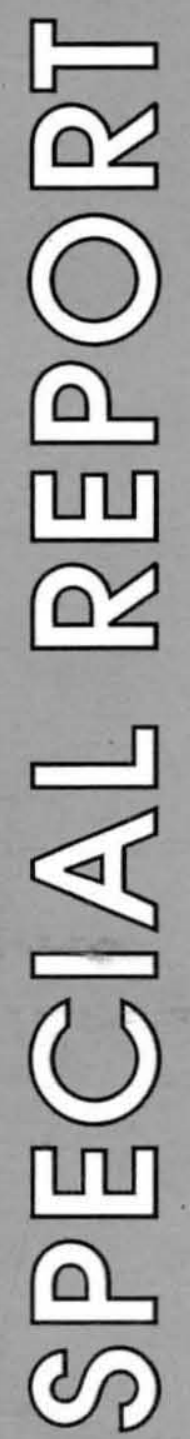


For conversion of SI metric units to U.S./British customary units of measurement consult ASTM Standard E380, Metric Practice Guide, published by the American Society for Testing and Materials, 1916 Race St., Philadelphia, Pa. 19103. 
Special Report 90-22

\section{Complex Formation Between Dimethyl Methylphosphonate and Hexafluoroisopropanol}

Daniel C. Leggett 


\section{PREFACE}

This report was prepared by Daniel C. Leggett, Research Chemist, of the Geochemical Sciences Branch, Research Division, U. S. Army Cold Regions Research and Engineering Laboratory. Funding for this research was provided by DA Project 4A161102AT24, Research in Snow, Ice and Frozen Ground, Task SS, Work Units 031, Chemical Persistence at Low Temperatures, and 020, Chemical Species Transport Phenomena in Frozen Ground.

The author thanks Dr. Patrick Black and Alan Hewitt for their technical review of this report. 


\title{
Complex Formation Between Dimethyl Methylphosphonate and Hexafluoroisopropanol
}

\author{
DANIEL C. LEGGETT
}

\section{INTRODUCTION}

Previous work on the partitioning of dimethyl methylphosphonate (DMMP) between water and organic solvents suggested that the controlling mechanism was H-bond formation between it and the solvent (Leggett 1990). For effective extraction of DMMP from water the solvent had to have $\mathrm{H}$-donor properties, although there was no direct correlation with its $\mathrm{pK}_{\mathrm{a}}$. The structural and electronic similarity between DMMP and some of the chemical agents (sarin, soman) suggested that solvent extraction methods for these compounds could be improved by using a more powerful $\mathrm{H}$-donor solvent such as trifluoroethanol or hexafluoroisopropanol.

Two research groups involved in the development of polymer coatings for vapor phase sorption of phosphorus esters have also identified the importance of $\mathrm{H}$ bonding sites (Barlow et al. 1987, Grate et al. 1988). One of the polymers used was hexafluorocarbinolsubstituted polystyrene, which contains the same active moiety as hexafluoro-isopropanol (HFIP), namely

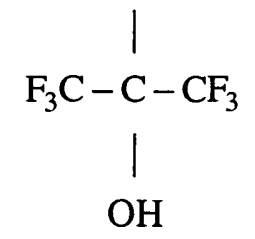

Barlow et al. (1987) reported equilibrium constants for complex formation between DMMP and HFIP based on spectroscopic data in ethylbenzene. I report here complex-formation constants for DMMP and HFIP in several solvents determined by a liquid-liquid partition method. These results are compared with those for similar compounds in the literature.

\section{Experimental}

The same protocol was followed as in the earlier work (Leggett 1990) except that the partitioning solvents were doped with a 10 -fold molar excess of HFIP:

$$
\left\{\frac{[\mathrm{HFIP}]}{[\mathrm{DMMP}]} \approx 10\right\} \text {. }
$$

Initial trials were plagued by emulsion of the organic phases and only the aqueous phases were analyzed. Since addition of excess sodium chloride gave rapid phase separation without emulsion formation in all cases, all reported measurements were performed in the presence of saturated $\mathrm{NaCl}$. Both phases were analyzed. The data were treated as follows. The aqueous phase concentration of DMMP in the presence of HFIP was assumed to be uncomplexed, and a corresponding estimate of free DMMP in the organic phase was calculated using the partition coefficient obtained earlier (Leggett 1990) on each system. The small correction was then subtracted from the measured organic phase concentration to obtain a corrected value for the complexed DMMP. The ratio of complexed to free DMMP was then taken to give a dimensionless complexation constant. A one-to-one complex was assumed to form according to the usual equation:

$$
\text { DMMP + HFIP } \Leftrightarrow \text { DMMP - HFIP }
$$

and the resulting equilibrium is

$$
\mathrm{K}_{\mathrm{eq}}=\frac{[\mathrm{DMMP}-\text { HFIP }]}{[\mathrm{DMMP}][\text { HFIP }]}
$$

To obtain $K_{\mathrm{eq}}$ the dimensionless constants obtained 
Table 1. Stability constants for DMMP-HFIP complexes in various solvents.

\begin{tabular}{lrrrr} 
& $\mathrm{K} *$ & $\mathrm{~K}_{\mathrm{eq}} \dagger$ & $\overline{\mathrm{K}}_{\mathrm{eq}}^{* * *}$ & $-\Delta \mathrm{G}_{f}^{\circ} \dagger \dagger$ \\
\hline Hexane & 1250.0 & 53,400 & 407,000 & 7.55 \\
Carbon disulfide & 64.7 & 3,510 & 58,300 & 6.41 \\
Carbon tetrachloride & 110.0 & 2,860 & 29,500 & 6.01 \\
Benzene & 26.4 & 650 & 7,350 & 5.20 \\
Chloroform & 2.9 & 73 & 910 & 3.98 \\
& & & & \\
\hline
\end{tabular}

$$
\begin{aligned}
& { }^{*} K=\frac{[\mathrm{DMMP}-\mathrm{HFIP}]}{[\mathrm{DMMP}]}(\text { dimensionless concentration }) \\
& \dagger K_{\mathrm{eq}}=\frac{[\mathrm{DMMP}-\mathrm{HFIP}]}{[\mathrm{DMMP}][\mathrm{HFIP}]}(\mathrm{L} / \mathrm{mole}) \\
& { }_{* * K_{\mathrm{eq}}}=\frac{[\mathrm{DMMP}-\mathrm{HFIP}]}{[\mathrm{DMMP}][\mathrm{HFIP}]}(\text { mole fraction }) \\
& \dagger \dagger-\Delta G_{f}^{\circ}=\mathrm{RT} \ln \overline{\mathrm{eq}}(\mathrm{cal} / \text { mole } \bullet \mathrm{K})
\end{aligned}
$$

above were simply divided by the free HFIP remaining in the organic phase. This was estimated by subtracting the amount complexed from the total added minus the amount remaining in the aqueous phase, the amount complexed being identical to the molar concentration of DMMP complexed. The fraction of HFIP remaining in aqueous solution was estimated from the relative detector responses for the HFIP peak in the two phases. Finally, the $K_{\text {cu }}$ in units of L/mole was multiplied by the reciprocal of the solvent molar volume $\left(V_{m}^{-1}\right)$ to obtain the dimensionless mole fraction form, $K_{\mathrm{cu}}$. The standard free energy of complexation, $\Delta G_{\mathrm{f}}^{\circ}$, was calculated from the usual relation, $\Delta G_{\mathrm{f}}^{\circ}=-\mathrm{RT} \ln K_{\mathrm{\alpha u}}$, at the experimental temperature of $294 \mathrm{~K}$.

\section{RESULTS AND DISCUSSION}

Table 1 summarizes the stability constants and standard free energies of formation for DMMP-HFIP complexes obtained in different solvents. The stability is markedly greater in hexane than in the more polar $\mathrm{H}$ bonding solvent, chloroform. Even benzene suppresses the formation constant considerably, evidently by interaction with either DMMP, HFIP, or both. Benzene can act as an electron-pair donor (Lewis base) towards HFIP. Partitioning of HFIP into benzene was greater than that into the other solvents (Table 2). Benzene may also behave as a Lewis acid (electron-pair acceptor) towards DMMP. However, DMMP was extracted very poorly from water by benzene (Leggett 1990; Table 2), indicating that DMMP-benzene association is of only secondary importance. On the other hand, chloroform interacts with both HFIP and DMMP (Leggett 1990; Table 2). This undoubtedly explains the relatively low $K_{\text {cu }}$ for HFIP-DMMP in chloroform. Surprisingly, even carbon tetrachloride and carbon disulfide, two solvents that are ordinarily thought of as inert, suppress the formation constant of DMMP-HFIP. This effect has been noted elsewhere (Higuchi et al. 1969), being attributed to weak $\mathrm{H}$-bonding with $\mathrm{Cl}$ and $\mathrm{S}$, but this does not explain why HFIP partitioning is greater into hexane than into $\mathrm{CS}_{2}$. Perhaps $\mathrm{CS}_{2}$ and $\mathrm{CCl}_{4}$ suppress complex formation by interacting as aprotic Lewis acids with the base DMMP. Since spectroscopic investigations are often done in $\mathrm{CCl}_{4}$, the purity of the observed stability constants in these cases can be questioned.

Barlow et al. (1987) found $K_{\mathrm{eq}}$ for HFIP-DMMP in ethyl benzene by spectroscopic measurements to be 21 $\mathrm{L} /$ mole at $25^{\circ} \mathrm{C}$, lower than any of the values in Table 1 . Ethyl benzene should be a stronger base than benzene toward HFIP because of the electron-donating substituent. Thus a value of $<650 \mathrm{~L} / \mathrm{mole}$ is consistent with the values reported here. The $\mathrm{pK}_{\mathrm{a}}$ of HFIP in water is 9.3 (Taft et al. 1969) similar to that of the m-fluoro- and piodo-substituted phenols (Higuchi et al. 1969); however, its heat of mixing with DMMP is greater than that of o-chlorophenol, pK 8.48 (Chang et al. 1987). $K_{\mathrm{cu}}$ for DMMP-HFIP is higher than that of $\mathrm{p}$-nitrophenol, $\mathrm{pK}_{\mathrm{a}}$ 7.15 , with tributyl phosphate and sarin (Higuchi et al. 1969), suggesting that the acidity of HFIP in nonaqueous media may be underestimated.

Table 2. Distribution of DMMP and HFIP, and DMMP + 10-fold excess HFIP between salt-saturated water and solvents.

\begin{tabular}{lccc} 
Solvent & $\log \mathrm{P}_{s}^{D M M P}$ & $\log \mathrm{P}_{s+\text { HFIP }}^{\text {DMMP }}$ & $\log \mathrm{P}_{s}^{\text {HFIP }}$ \\
\hline Hexane & -2.46 & 0.64 & 0.15 \\
Carbon disulfide & -1.48 & 0.38 & -0.03 \\
Carbon tetrachloride & -1.00 & 1.04 & 0.49 \\
Benzene & -0.67 & 0.77 & 1.22 \\
Chloroform & 0.97 & 1.56 & 1.02 \\
\hline
\end{tabular}

*Includes both free and complexed HFIP; correction for HFIP complexed by DMMP lowers these values by no more than $0.09 \log$ units. 
Table 3. Estimated stability constants of HFIP with phosphonate esters in $\mathrm{CCl}_{4}$ at $21^{\circ} \mathrm{C}$.

\begin{tabular}{llll} 
Acceptor & $\mathrm{K}_{e q}$ & $\log \mathrm{K}_{e q}$ & Ref. \\
\hline Dimethyl ethyl phosphonate & 1680 & $3.23 \pm 0.10$ & Taft et al. (1969) \\
Diethyl chloromethyl phosphonate & 2280 & $3.36 \pm 0.10$ & Taft et al. (1969) \\
Diethyl methylphosphonate & 4130 & $3.62 \pm 0.10$ & Taft et al. (1969) \\
Dimethyl methylphosphonate & 2860 & $3.46 \pm 0.10$ & This work
\end{tabular}

The strength of DMMP as a base is also important in determining the magnitude of $K_{\text {ci }}$. According to Hudson (1965) phosphonates should be stronger bases than phosphates because of the electron-releasing methyl group attached to phosphorus. The octanol-water partition coefficients of DMMP and trimethyl phosphate (TMP) were found to be -1.13 and -0.60 , respectively (Leggett 1987), which also suggests greater basicity for DMMP, with water as the proton donor. Empirical correlations (linear free energy relationships) given by Taft et al. (1969) also support this general conclusion. Predicted values for stability constants of HFIP with phosphonates similar to DMMP at $21^{\circ} \mathrm{C}$ were obtained by linear interpolation of the data of Taft et al. (1969) for $\log K_{\text {cy }}$ with $T(\mathrm{~K})$. These are shown in Table 3. The reported measurement is in good agreement with these predicted values. $\Delta G_{\mathrm{f}}^{\circ}$ of complexation (Table 1) supports the $\mathrm{H}$-bonding mechanism and is similar to the measured heat of complexation in ethyl benzene, 6.4 $\mathrm{kcal} / \mathrm{mole}-\mathrm{K}$ (Barlow et al. 1987), which is probably low due to interaction of HFIP with the solvent.

In concluding, HFIP was found to complex strongly with DMMP, as inferred from solvent extraction data (Leggett 1990). The measured complex-formation constant was greater in hexane than in other solvents, due to competing interactions with HFIP in these solvents. The formation constant is similar in magnitude to a spectroscopically measured heat of complexation (Barlow et al. 1987), which strongly supports an $\mathrm{H}$ bonding mechanism. Small amounts of .HFIP were found to markedly increase the extraction of DMMP into nonaqueous solvents; because of mass action, however, most complete extraction will be obtained when pure HFIP is used as the extraction solvent. By analogy with the correlations of Taft et al. (1969) and the data reported by Higuchi et al. (1969), related compounds such as phosphates, phosphites, phosphonofluoridates and other phosphonates all should be well-extracted from water by HFIP.

\section{LITERATURE CITED}

Barlow, J.W., P.E. Cassidy, D.R. Lloyd, C-J. You, Y. Chang, P.C. Wong and J. Noriyan (1987) Polymer sorbents for phosphorus esters: II. Hydrogen bond driven sorption in fluoro-carbinol substituted polystyrene. Polymer Science and Engineering, 27(10): 703-715. Chang, Y., J. Noriyan, D.R. Lloyd and J.W. Barlow (1987). Polymer sorbents for phosphorus esters: 1. Selection of polymers by analog calorimetry. Polymer Science and Engineering, 27(10): 693-702.

Grate, J.W., A. Snow, D.S. Ballantine, H. Wohltjen, M.H. Abraham, R.A. McGill and P. Sasson (1988) Determination of partition coefficients from surface acoustic wave vapor sensor responses and correlation with gas-liquid chromatographic partition coefficients. Analytical Chemistry, 60: 869-875.

Higuchi, T., J.H. Rivards, S.S. Davis, A. Kamada, J.P. Hou, M. Nakano, N.I. Nakano and I.H. Pitman (1969) Solvency and hydrogen bonding interactions in nonaqueous systems. Journal of Pharmaceutical Sciences, 58(6): 661-671.

Hudson, R.F. (1965) Structure and Mechanism in Organo-phosphorus Chemistry. New York: Academic Press:

Leggett, D.C. (1987) Sorption of chemical agents and simulants: Measurement and estimation of octanolwater partition coefficients. USA Cold Regions Research and Engineering Laboratory, Special Report 87-18.

Leggett, D.C. (1990) Solvent/water partitioning and extraction of dimethyl methyl phosphonate: Importance of H-bonding. USA Cold Regions Research and Engineering Laboratory, Special Report 90-21.

Taft, R.W., D. Gurka, L. Joris, P. von R. Schleyer and J.W. Rakshys (1969) Studies of hydrogen-bonded complex formation with p-fluorophenol. V. Linear free energy relationships with $\mathrm{OH}$ reference acids. Journal of the American Chemical Society, 91(17): 4801-4808.

*US GOVERNMENT PRINTING OFFICE:1990-700-057/22020 
Public reporting burden for this collection of information is estimated to average t hour per response, including the time for reviewing instructions, searching existing data sources, gathering and maintaining the data needed, and completing and reviewing the collection of information. Send comments regarding this burden estimate or any other aspect of this collection of information, including suggestion for reducing this burden, to Washington Headquarters Services, Directorate for Information Operations and Reports, 1215 Jefferson Davis Highway, Suite 1204, Arlington, VA 22202-4302, and to the Otfice of Management and Budget, Paperwork Reduction Project (0704-0188), Washington, DC 20503.

\begin{tabular}{|l|l|l}
\hline 1. AGENCY USE ONLY (Leave blank) & $\begin{array}{c}\text { 2. REPORT DATE } \\
\text { June } 1990\end{array}$ & 3. REPORT TYPE AND DATES COVERED
\end{tabular}

\begin{tabular}{|l|l|l|}
\hline 4. TITLE AND SUBTITLE & 5. FUNDING NUMBERS
\end{tabular}

Complex Formation Between Dimethyl Methylphosphonate and

Hexafluoroisopropanol

PR: 4A161102AT24

TA: SS

6. AUTHORS

Daniel C. Leggett

WU: 020 and 031

8. PERFORMING ORGANIZATION REPORT NUMBER

U.S. Army Cold Regions Research and Engineering Laboratory

72 Lyme Road

Special Report 90-22

Hanover, New Hampshire 03755-1290

9. SPONSORING/MONITORING AGENCY NAME(S) AND ADDRESS(ES)

10. SPONSORING/MONITORING AGENCY REPORT NUMBER

Office of the Chief of Engineers

Washington, D.C. 20314-1000

11. SUPPLEMENTARY NOTES

12a. DISTRIBUTION/AVAILABILITY STATEMENT

12b. DISTRIBUTION CODE

Approved for public release; distribution is unlimited.

Available from NTIS, Springfield, Virginia 22161

13. ABSTRACT (Maximum 200 words)

A solvent/water partitioning method was used to measure the complex formation between dimethyl methylphosphonate (DMMP) and hexafluoroisopropanol (HFIP). The highest formation constant was obtained when n-hexane was used as the partitioning solvent. Other solvents all interfered to some extent with complex formation, probably by interacting with HFIP. The log formation constant in carbon tetrachloride was $3.46 \pm 0.10$ at $21^{\circ} \mathrm{C}$, which was similar to literature estimates for other phosphonates. The data support formation of $\mathrm{H}$-bond charge transfer complexes as the mechanism for HFIP interaction with phosphonates and as primarily responsible for HFIP extraction of these compounds from water.

\begin{tabular}{|ll|l|}
\hline 14. SUBJECT TERMS & \multicolumn{2}{l}{ Complexation } \\
& $\begin{array}{l}\text { Dimethyl Methylphosphonate (DMMP) } \\
\text { Hexafluoroisopropanol (HFIP) }\end{array}$ \\
\hline $\begin{array}{l}\text { 17. SECURITY CLASSIFICATION } \\
\text { OF REPORT } \\
\text { UNCLASSIFIED }\end{array}$ & $\begin{array}{l}\text { 18. SECURITY CLASSIFICATION } \\
\text { OF THIS PAGE } \\
\text { UNCLASSIFIED }\end{array}$ & $\begin{array}{l}\text { 19. SECURITY CLASSIFICATION } \\
\text { OF ABSTRACT } \\
\text { UNCLASSIFIED }\end{array}$ \\
\hline
\end{tabular}

15. NUMBER OF PAGES

16. PRICE CODE

20. LIMITATION OF ABSTRACT

UL

NSN 7540-01-280-5500 